\title{
Danos na cultura do milho em função da redução de área foliar por desfolha artificial e por doenças
}

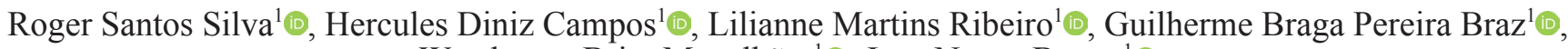 \\ Wanderson Brito Magalhães ${ }^{1} \mathbb{C}$, Jane Nunes Bueno ${ }^{1}[0$
}

\author{
${ }^{1}$ Programa de Pós-graduação em Produção Vegetal (PPGPV), Universidade de Rio Verde - UniRV. Fazenda Fontes do Saber, Caixa Postal 104, \\ CEP: 75901-970. Rio Verde, GO, Brasil. \\ Autor para correspondência: Guilherme Braga Pereira Braz (guilhermebrag@gmail.com) \\ Data de chegada: 15/11/2019. Aceito para publicação em: 14/10/2020.
}

\section{RESUMO}

$10.1590 / 0100-5405 / 231093$

Silva, R.S.; Campos, H.D.; Ribeiro, L.M.; Braz, G.B.P.; Magalhães, W.B.; Bueno, J.N. Danos na cultura do milho em função da redução de área foliar por desfolha artificial e por doenças. Summa Phytopathologica, v.46, n.4, p.313-319, 2020.

\begin{abstract}
Danos causados por doenças que ocorrem durante os estádios vegetativos no milho resultam em redução do rendimento de grãos, e o controle químico é uma das estratégias que possibilita a redução dos danos. O objetivo desse trabalho foi quantificar o dano em milho em função da redução da área foliar causada pelo complexo de doenças, associando ou não a remoção de folhas em diferentes posições da planta. O experimento foi conduzido no campo, no delineamento de blocos casualizados com quatro repetições e tratamentos dispostos em arranjo fatorial $10 \times 3$. O primeiro fator correspondeu a associação de dois fungicidas em diferentes doses, combinados com desfolhas artificiais
\end{abstract}

realizadas nas plantas no momento da primeira aplicação. O segundo fator consistiu em diferentes estádios de aplicação (VT, R1 e R2). O híbrido utilizado foi o Fórmula $\mathrm{TL}^{\circledR}$, suscetível à cercosporiose, ferrugem polissora e mancha-branca. Foi avaliado o progresso das doenças, índice de área foliar e o rendimentos de grãos. Aplicações preventivas (estádio fenológico VT) de fungicidas, independentemente da remoção de folhas na planta, proporcionou menor progresso das doenças e menores danos. Maiores valores significativo de massa de grãos e produtividade foram obtidos com uso de fungicidas sem a remoção de folhas, independentemente do estádio fenológico da aplicação.

Palavras-chave: doenças foliares, rendimento grãos, Zea mays.

\section{ABSTRACT}

Silva, R.S.; Campos, H.D.; Ribeiro, L.M.; Braz, G.B.P.; Magalhães, W.B.; Bueno, J.N. Damage to the corn crop due to the reduction of leaf area by artificial defoliation and diseases. Summa Phytopathologica, v.46, n.4, p.313-319, 2020.

Damage caused by diseases that occur during the vegetative stages of corn results in decreased grain yield, and chemical control is one of the strategies to allow damage reduction. The objective of this study was to quantify the damage to corn plants as a function of leaf area reduction caused by the disease complex, associated or not with leaf removal from different positions in the plant. The experiment was carried out in the field, in a completely randomized block design with four replicates and $10 \times 3$ factorial arrangement of treatments. The first factor corresponded to the association of two fungicides at different doses, combined with artificial defoliation at the first fungicide spraying. The second factor consisted of application at different stages (VT, R1 and R2). The used hybrid was Formula $\mathrm{TL}^{\circledR}$, which is susceptible to cercosporiosis, polysora rust and white spot. Disease progress, leaf area index and grain yield were evaluated. Preventive application of fungicides (phenological stage VT), regardless of leaf removal from the plant, provided less disease progress and less damage. Higher significant values of grain mass and yield were obtained with fungicide application without leaf removal, regardless of the phenological stage receiving the application.

Keywords: leaf diseases, grain yield, Zea mays.

O milho (Zea mays L.) é uma planta de ciclo anual, pertencente à família Poaceae, adaptada a vários ambientes, consistindo no cereal de maior área de cultivo no mundo (21). No Brasil, o cultivo sucessivo do milho (safra e safrinha), monocultura, irrigação sem critérios técnicos e sistema de plantio direto sem rotação de culturas tem contribuído para o aumento da incidência e severidade de algumas doenças (9).

Dentro do complexo de doenças foliares no milho, as com maior ocorrência são de origem fúngica, destacando-se a cercosporiose (Cercospora zeae-maydis Tehon \& Daniels), mancha branca [Phaeosphaeria maydis (Henn.) Rane, Payak e Renfro] e ferrugem polissora (Puccinia polysora Underw.) (9; 19). Estas doenças são de importância na maioria das regiões produtoras de milho do País, estimando-se que os danos podem ultrapassar $40 \%$ na produção de grãos em híbridos suscetíveis, quando há condições ambientais favoráveis ao desenvolvimento das doenças (5).

O potencial produtivo do milho começa a ser definido quando a cultura alcança os estádios fenológicos V4 e V5, o que corresponde de quatro a cinco folhas totalmente expandidas. Essa fase é importante, pois a planta origina os primórdios do pendão e da espiga e, nessa fase ocorrerá a diferenciação de todas as folhas. O meristema apical da planta de milho ainda se encontra abaixo da superfície do solo quando a planta se encontra no estádio fenológico V5, o que permite com que a mesma se recupere de danos causados na parte aérea quando se encontra nessa fase. Após essa fase, a recuperação dos danos na parte aérea é limitada (14).

O período crítico da cultura do milho na definição da produtividade estende-se do pré-florescimento até o início do enchimento de grãos, uma vez que ocorrências de estresses, seja hídrico ou até mesmo 
redução da área foliar por doenças, ocasionam grande impacto sobre a produção da cultura $(3 ; 6)$. Qualquer redução da área foliar sadia após a floração vai desencadear diminuição na taxa fotossintética, gerando prejuízos no enchimento dos grãos e ainda demandar o uso de reservas provenientes do colmo da planta, reservas essas que em falta podem favorecer a ocorrência de doenças e ainda podem ocasionar o tombamento ou acamamento das plantas (16).

A área foliar sadia tem aumento gradativo na planta, até que a mesma atinja seu máximo desenvolvimento, a partir daí se inicia um decréscimo devido à senescência das folhas mais velhas e, dessa forma, quanto mais rápido a cultura atingir o índice de área foliar sadia máximo, e quanto mais tempo a planta conseguir manter essa área foliar, maior será seu rendimento (20). O maior índice foliar da cultura do milho é obtido na fase de pendoamento, onde se inicia o período crítico da cultura, e se estende até a fase de grão pastoso (R3), e as folhas que apresentam os maiores índices de área foliar são as folhas da espiga e as acima e abaixo da espiga, nas quais uma redução de área foliar, nesse período, pode acarretar em redução significativa na produtividade e na qualidade de colmo e grãos (23).

Conhecer a necessidade de preservação da área foliar sadia a partir desses estádios fenológicos, bem como suas funções, são importantes para tomada de decisão de aplicação de fungicidas. Portanto, a definição do potencial produtivo da cultura está intimamente relacionada com as condições ótimas de temperatura e umidade durante as fases de crescimento e desenvolvimento, sendo ideal a manutenção da área foliar sadia mais preservada possível. O controle químico pode ser um método eficaz no manejo de doenças foliares e na manutenção da sanidade da cultura quando realizado no momento certo de aplicação dos fungicidas, possibilitando manter o potencial produtivo da cultura (8).

Geralmente, o momento da aplicação depende da intensidade das doenças presentes durante o ciclo da cultura e do nível da reação de cada híbrido de milho (23). Produtos químicos para o controle de doenças se fazem usuais, onde fungicidas do grupo dos triazóis (IDMs) e suas misturas com estrobilurinas (IQes) em sistemas de produção de médias e alta tecnologia têm sido uma ferramenta útil para a cultura do milho, expressando seu potencial produtivo e sendo uma prática economicamente viável.

Assim como para outras culturas, no caso específico do milho, por ser uma espécie $\mathrm{C} 4$, reduções na área foliar das plantas pode comprometer a produtividade final, visto que haverá uma diminuição na produção de assimilados que serão redistribuídos para o enchimento dos grãos. $\mathrm{O}$ entendimento das relações entre redução de área foliar associado ao uso de fungicidas para o controle de doenças foliares pode indicar a importância de se proceder ao manejo destas no estádio recomendado da cultura.

Este trabalho visou avaliar danos na cultura do milho em função da redução da área foliar causada por complexo de doenças, associando ou não à remoção de folhas em diferentes posições da planta.

\section{MATERIAL E MÉTODOS}

O experimento foi realizado no campo no município de Rio Verde, GO, no período de fevereiro a julho de 2014. Segundo a classificação de Köppen, o clima do município recebe o nome de tropical com estação seca, caracterizado por apresentar chuvas mais intensas no verão em comparação com o inverno (25). Na Figura 1 estão apresentados os dados do ambiente relacionados à temperatura média do ar e às precipitações pluviais durante o período de condução do experimento.

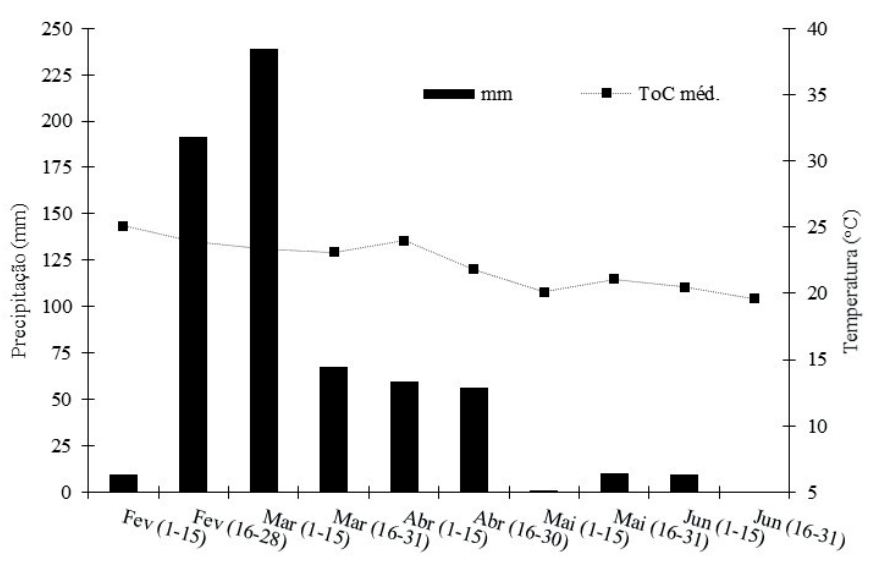

Figura 1. Temperatura média e precipitação pluvial registradas durante o período de condução do experimento. Rio Verde (GO), 2014.

Previamente à implantação do experimento, foi realizada análise de solo da camada de 0 a $20 \mathrm{~cm}$ de profundidade, com as seguintes propriedades físico-químicas: $\mathrm{pH}\left(\mathrm{CaCl}_{2}\right)=5,1 ; 1,84 \mathrm{cmol} \mathrm{dm}^{-3} \mathrm{de}$

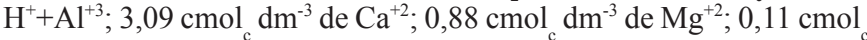
$\mathrm{dm}^{-3} \mathrm{de} \mathrm{K}^{+} ; 6,54 \mathrm{mg} \mathrm{dm}^{-3}$ de P; 14,80 $\mathrm{g} \mathrm{dm}^{-3} \mathrm{de} \mathrm{CO}^{2} 485 \mathrm{~g} \mathrm{~kg}^{-1}$ de argila, $133 \mathrm{~g} \mathrm{~kg}^{-1}$ de silte, $382 \mathrm{~g} \mathrm{~kg}^{-1}$ de areia (textura argilosa). A adubação no sulco de semeadura foi realizada com o formulado 07-25-25 (N-P $\mathrm{O}_{5}-$ $\mathrm{K}_{2} \mathrm{O}$ ), na dose equivalente a $300 \mathrm{~kg} \mathrm{ha}^{-1}$, e no estádio fenológico V5 realizada uma adubação nitrogenada em cobertura com aplicação de $200 \mathrm{~kg} \mathrm{ha}^{-1}$ de ureia.

O híbrido de milho utilizado foi o Fórmula $\mathrm{TL}^{\circledR}$, que apresenta suscetibilidade as principais doenças foliares da cultura, destacandose a cercosporiose, ferrugem polissora e a mancha -branca (24). $\mathrm{O}$ espaçamento entrelinhas utilizado foi de $50 \mathrm{~cm}$, e densidade de semeadura de 3,0 sementes $\mathrm{m}^{-1}$, de acordo com a recomendação para o híbrido utilizado. Os tratamentos fitossanitários (com inseticidas e herbicidas) foram realizados de acordo com os recomendados técnicas para o milho, avaliando-se a infestação de plantas daninhas e incidência de pragas na cultura, sendo realizados levantamentos semanais para certificar que não houvesse reduções na produtividade da cultura pela ação desses agentes.

O delineamento experimental utilizado foi em blocos ao acaso com quatro repetições, com os tratamentos dispostos em arranjo fatorial 10 x 3. O primeiro fator foi constituído pela aplicação da associação entre dois fungicidas em doses distintas, em combinação com simulações de desfolhas artificiais realizadas nas plantas no momento da primeira aplicação do experimento (Tabela 1). O segundo fator correspondeu à aplicação dos fungicidas em diferentes estádios fenológicos: prépendoamento (VT), florescimento (R1) e grão leitoso (R2).

As desfolhas artificias foram realizadas em diferentes porções do colmo, adotando-se a divisão em terços, conforme detalhado na Figura 2. As unidades experimentais foram compostas por oito fileiras de 5 $\mathrm{m}$ de comprimento. Como bordadura, foram consideradas as quatro fileiras centrais, eliminando-se $0,5 \mathrm{~m}$ de cada extremidade da unidade experimental, totalizando área útil igual a $8 \mathrm{~m}^{2}$.

Para cada momento da aplicação do fungicida, foram realizadas duas aplicações com intervalo de quinze dias entre a primeira e a segunda (Tabela 2). No momento da primeira aplicação (estádio fenológico VT) havia na testemunha a presença da cercosporiose, ferrugem polissora e mancha-branca, apresentando as respectivas notas: 12,$34 ; 14,16$ e $16,78 \%$, de acordo com a escala de Malagi et al. (15). Para a aplicação foliar, foi utilizado um pulverizador costal 
Tabela 1. Relação de tratamentos compostos por níveis de desfolha artificial associados a aplicação de fungicidas no milho cultivado em segunda da safra. Rio Verde (GO), 2014

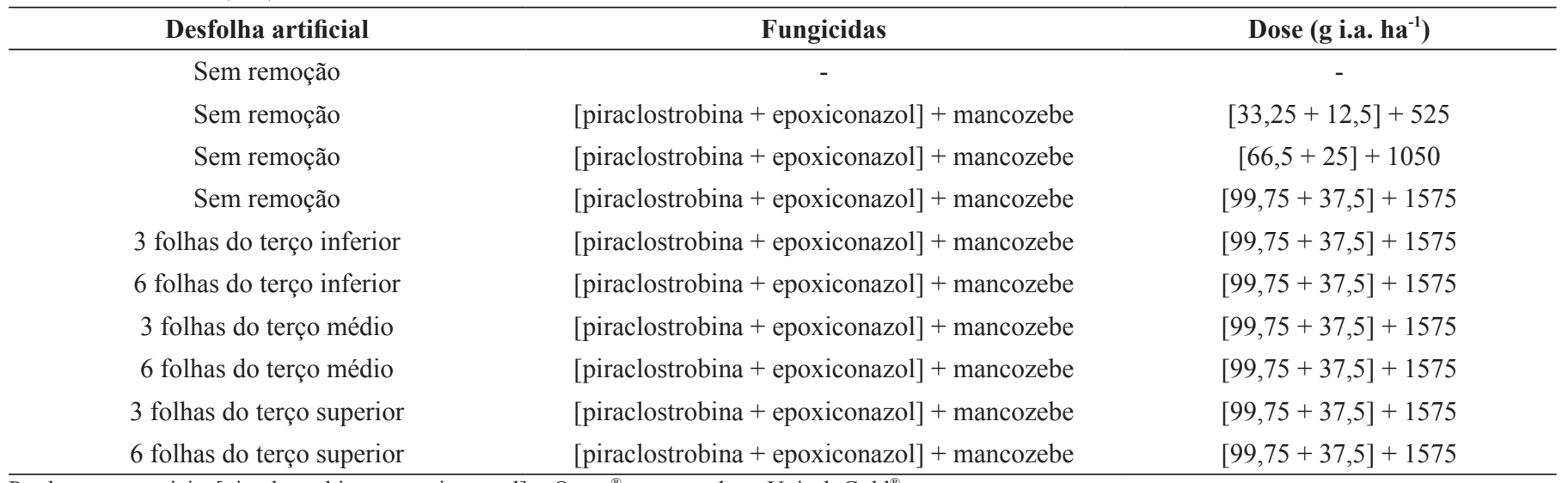
Produtos comerciais: [piraclostrobina + epoxiconazol] $=$ Opera $^{\circledR} ;$ mancozebe $={\text { Unizeb } \text { Gold }^{\circledR}}^{\text {. }}$

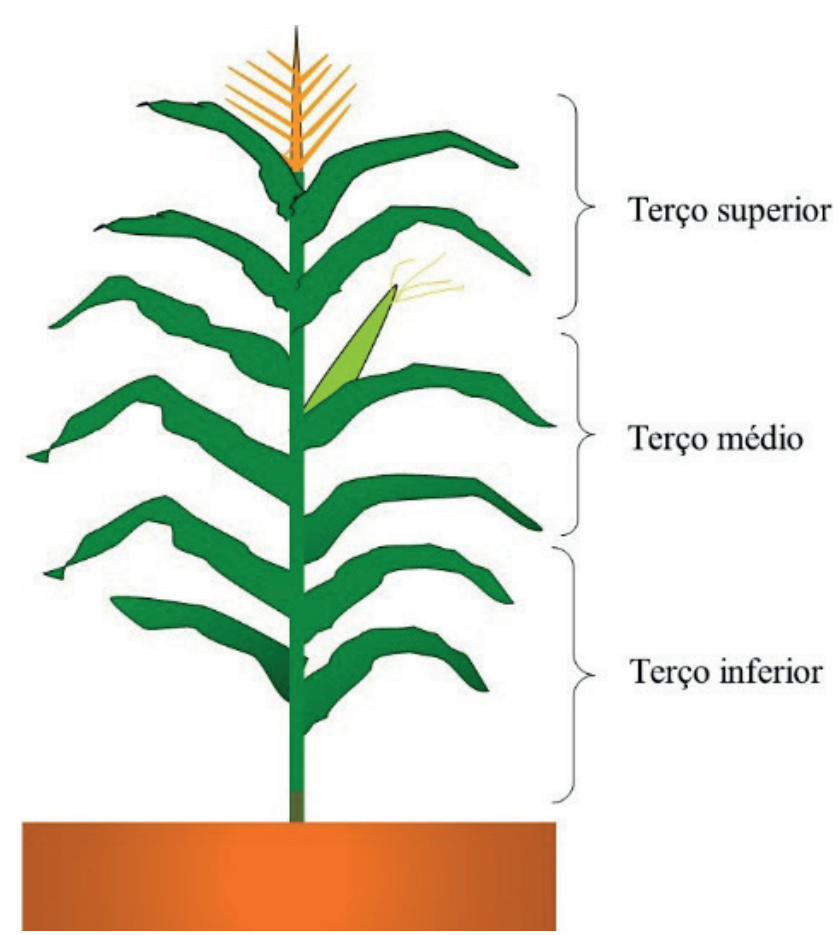

Figura 2. Divisão esquemática da planta de milho de acordo com a distribuição de folhas em cada terço da planta.

pressurizado a $\mathrm{CO}_{2}$, contendo uma barra de três metros de comprimento e seis bicos de pulverização com pontas do tipo leque duplo TJ 110.02, espaçados a $0,5 \mathrm{~m}$. O volume de calda utilizado foi de $200 \mathrm{~L} \mathrm{ha}^{-1}$ sob pressão de $30 \mathrm{lb} \mathrm{pol}^{-2}$. Visando garantir a melhor cobertura das plantas, a pulverização foi realizada com a barra posicionada a $0,3 \mathrm{~m}$ acima do dossel das plantas.

Durante as aplicações, as condições ambientais foram monitoradas com auxílio do aparelho Kestrel 3000. Para tanto, foram avaliadas: a temperatura, a umidade relativa do ar e as velocidades médias e máximas do vento no início e no fim das aplicações. As condições ambientais durante as aplicações encontravam-se ótimas ou próximas àquelas tidas como ideais, quando a temperatura se encontra abaixo de $30^{\circ} \mathrm{C}$, umidade relativa acima de $55 \%$ e velocidade do vento abaixo de $10 \mathrm{~km} \mathrm{~h}^{-1}$.

Foram avaliadas as variáveis área abaixo da curva do progresso da doença (AACPD) em função da severidade da doença, índice de área foliar total (sadia) (AFT), percentual de área foliar lesionada (\%AFL), percentual total de área foliar perdida (\%TAFP) (área foliar lesionada + área foliar retirada artificialmente) e rendimentos (massa de mil grãos e produtividade).

Para avaliar a severidade das doenças cercosporiose, ferrugem polissora e mancha branca separadamente nos três momentos da aplicação dos fungicidas, foram consideradas as folhas da espiga e a segunda folha, de cima para baixo, no ápice nas plantas de milho, estimando o percentual de área lesionada pela doença na folha. Para essas avaliações foram tomadas folhas de quatro plantas ao acaso por parcela nos estádios fenológicos VT, R1 e R2.

O progresso das doenças, ao longo do tempo, foi calculado através da área abaixo da curva de progresso da doença (AACPD) utilizando a fórmula:

$$
\mathrm{AACPD}=\sum_{i=1}^{n}\left[\left(\mathrm{Y}_{\mathrm{i}+1}+\mathrm{Y}_{\mathrm{i}}\right) / 2\right]\left[\mathrm{X}_{\mathrm{i}+1}-\mathrm{X}_{\mathrm{i}}\right]
$$

Onde $\mathrm{Y}_{\mathrm{i}}$ é a severidade na iésima observação; $\mathrm{X}_{\mathrm{i}}$ é o tempo (dias) na iésima observação e n é o número total de avaliações (21). O índice

Tabela 2. Condições ambientais no momento das aplicações dos fungicidas. Rio Verde (GO), 2014

\begin{tabular}{|c|c|c|c|c|c|c|}
\hline & \multicolumn{2}{|c|}{ Estádio fenológico VT } & \multicolumn{2}{|c|}{ Estádiao fenológico R1 } & \multicolumn{2}{|c|}{ Estádio fenológico R2 } \\
\hline & $1^{a}$ & $2^{a}$ & $1^{a}$ & $2^{a}$ & $1^{\mathrm{a}}$ & $2^{\mathrm{a}}$ \\
\hline Data & $31 / 03 / 2014$ & $15 / 04 / 2014$ & $08 / 04 / 2014$ & $23 / 04 / 2014$ & $18 / 04 / 2014$ & $03 / 05 / 2014$ \\
\hline UR $(\%)$ & 71,75 & 69,05 & 77 & 64,25 & 66,5 & 62,6 \\
\hline $\mathrm{VV}\left(\mathrm{km} \mathrm{h}^{-1}\right)$ & 3,75 & 4,2 & 5,85 & 7 & 3,6 & 5,35 \\
\hline
\end{tabular}

$\mathrm{UR}=$ Umidade relativa do ar; $\mathrm{VV}=$ Velocidade do vento. 
de área foliar (IAF) foi calculado conforme proposto por Fancelli e Dourado Neto (11). Ou seja, IAF $=$ (número de plantas por $\mathrm{m}^{2} \mathrm{x} \mathrm{AF}$ ) / $10000 \mathrm{~m}^{2}$ de acordo com a fórmula: AF (área foliar $)=[(\mathrm{Cf} \mathrm{x} \mathrm{Lf}) \mathrm{x}$ $0,7]$. Onde: $\mathrm{Cf}=$ comprimento da folha; $\mathrm{Lf}=$ largura da folha e 0,7 é a constante de ajuste da área da folha do milho, conforme relacionado pelos autores. Para o cálculo de área foliar por planta, quantificou-se o número médio de folhas por planta, cada planta apresentava doze folhas.

Com os dados da severidade e da área foliar retirada artificialmente da planta, calculou-se a área foliar total $\left(\mathrm{cm}^{2}\right)$ na planta em cada tratamento, o percentual de área foliar perdida por doença e total de área foliar perdida (porcentagem de área perdida por doença + porcentagem de área foliar perdida artificialmente).

Para determinação da massa de mil grãos $(\mathrm{g})$ e produtividade $(\mathrm{kg}$ $\mathrm{ha}^{-1}$ ), foi realizada a colheita manual, das espigas de todas as plantas presentes na área útil da parcela. Após esse processo, foi realizada a trilha das espigas e determinação da massa de mil grãos e produtividade, procedendo-se a correção de umidade para $13 \%$.

A análise estatística foi realizada com o software SISVAR (12). Os dados foram submetidos à análise de variância pelo teste $\mathrm{F}(p \leq 0,05)$ e quando constatado efeito significativo entre os fatores, ou entre os níveis de cada fator, as médias dos fatores relacionados ao primeiro fator (desfolha e fungicidas) foram comparadas pelo teste Scott-Knott $(p \leq 0,05)$ e para o segundo fator (época de aplicação), foi empregado o teste Tukey $(p \leq 0,05)$.

\section{RESULTADOS E DISCUSSÃO}

Para evolução da ferrugem polissora, pelos valores expressos pela $\mathrm{AACPD}$, fica evidenciado que as maiores áreas foram registradas nas plantas presentes na testemunha sem fungicidas e nos tratamentos com menores doses da associação entre os fungicidas, independentemente da época de aplicação dos fungicidas (Tabela 3). Em relação às épocas de aplicação, ficou evidenciado que à medida que há um retardamento (aplicações tardias, estádios fenológicos R1 e R2) na aplicação de fungicidas, verifica-se aumento no progresso da severidade da doença.

Os resultados da AACPD para ferrugem polissora indicam que visando ao controle químico desta doença na cultura do milho, dois fatores são imprescindíveis, estando primeiro relacionado ao uso de doses mais elevadas dos fungicidas, e o segundo acerca da necessidade de se proceder as aplicações mais precocemente (estádio fenológico VT). A constatação da necessidade de se proceder a aplicações preventivas de fungicidas visando ao controle de ferrugem polissora no milho já foi relatada anteriormente na literatura, uma vez que a aplicação

Tabela 3. Área abaixo da curva de progresso da doença (AACPD) para ferrugem polissora, mancha branca e cercosporiose em plantas de milho submetidas a diferentes épocas de controle. Rio Verde (GO), 2014

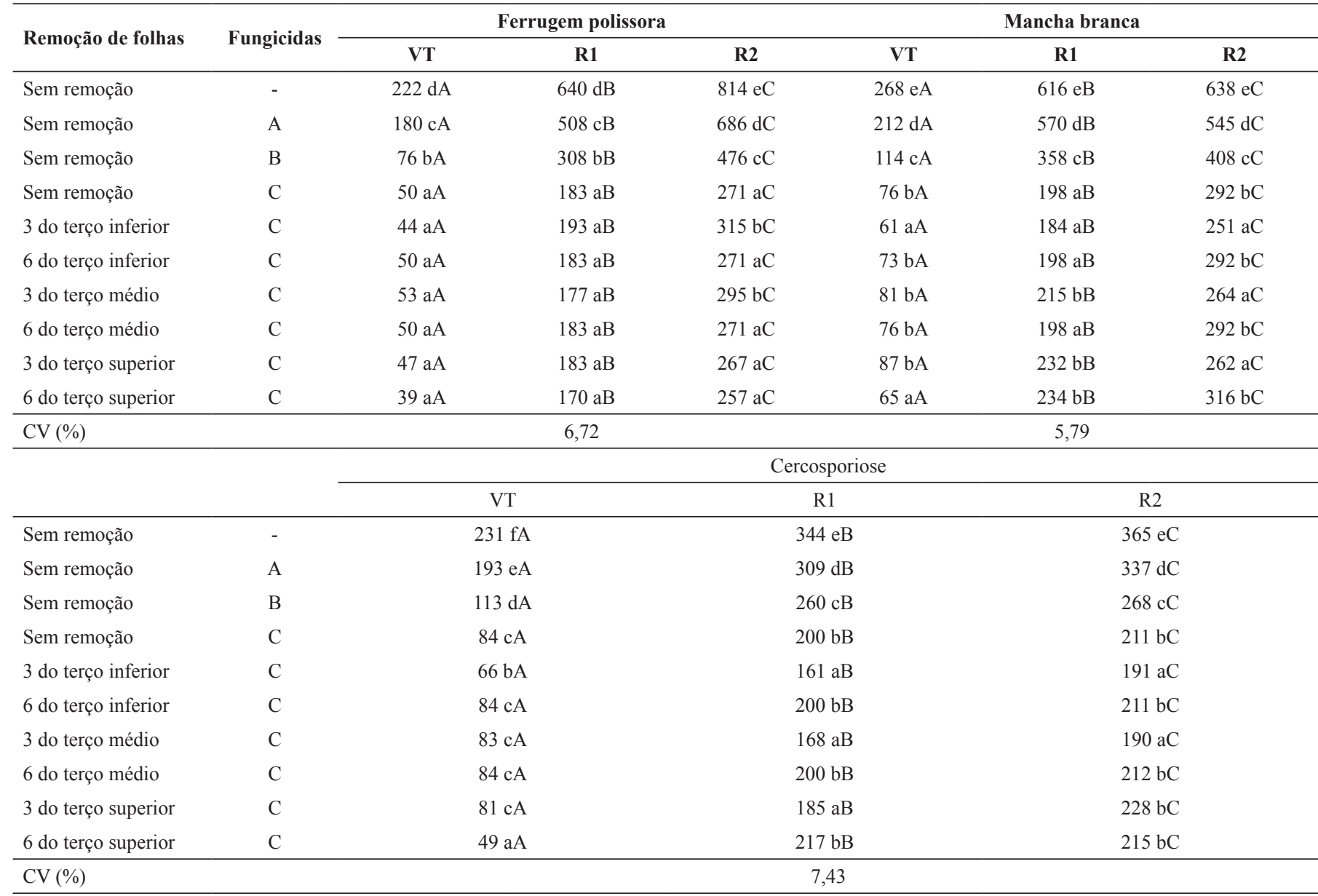

Fungicidas: $\mathrm{A}=[$ piraclostrobina + epoxiconazol $]+$ mancozebe $\left([33,25+12,5]+525 \mathrm{~g} \mathrm{ha}^{-1}\right) ; \mathrm{B}=[$ piraclostrobina + epoxiconazol $]+$ mancozebe $([66,5+25]+1050$ $\left.\mathrm{g} \mathrm{ha}^{-1}\right) ; \mathrm{C}=[$ piraclostrobina + epoxiconazol $]+$ mancozebe $\left([99,75+37,5]+1575 \mathrm{~g} \mathrm{ha}^{-1}\right)$. Médias seguidas pela mesma letra minúscula na coluna e maiúscula na linha não diferem entre si pelo teste Scott-Knott e Tukey $(p \leq 0,05)$, respectivamente. 
da associação de produtos IDMs e IQos no estádio V8 proporcionou $93,4 \%$ de controle (17), ocasião na qual a severidade da doença ainda era baixa $(0,51 \%)$.

Para a mancha-branca, a menor evolução da doença foi observada quando se retirou três folhas do terço inferior e 6 folhas do terço superior no estádio fenológico VT; 3 folhas e 6 folhas do terço inferior, 6 folhas do terço médio e, quando não se retirou folhas (planta com 12 folhas) em aplicação do fungicida na dose recomendada no estádio fenológico $\mathrm{R} 1$; e 3 folhas do terço inferior, médio e superior no estádio fenológico R2 (Tabela 3). Assim como observado para ferrugem polissora, quando se comparou as três épocas de aplicação dos fungicidas, observou-se que o manejo iniciado de forma antecipada, em estádios fenológicos mais precoces (VT), houve redução na curva de progresso da doença.

As folhas inseridas em diferentes posições do colmo contribuem diretamente com a quantidade de metabólitos que são distribuídos para toda a planta. Os carboidratos acumulados nos grãos de milho, cerca de $50 \%$ deles, são sintetizados nas folhas do terço superior do colmo, $30 \%$ são provenientes do terço médio e os outros $20 \%$ advêm das folhas distribuídas na parte basal da planta (13). Alvim et al. (2) observaram que toda a área foliar tem sua participação na produção de fotoassimilados, que são convertidos para produção de grãos, porém, a área foliar que permanece fisiologicamente acima da espiga apresenta contribuição mais eficiente no incremento de produtividade.

Ao avaliar o progresso da cercosporiose nas plantas de milho, verificou-se menores severidades quando se retiraram 6 folhas do terço superior no estádio VT; 3 folhas do terço inferior, médio e superior no estádio R1; e 3 folhas do terço inferior e médio no estádio R2 (Tabela 3). Quando se comparou as três épocas de controle, observouse maior progresso da cercosporiose quando iniciada a aplicação em estádio fenológico mais avançado (R2), registrando valor de AACPD equivalente a 365 , corroborando com os resultados obtidos para as demais doenças foliares avaliadas. Moratelli et al. (17) também avaliaram a influência do estádio fenológico e aplicações de fungicidas para o controle de doenças foliares no milho, constatando-se que o uso destes de maneira preventiva (estágio vegetativo), quando a doença ainda não se apresenta com alta severidade, proporcionou redução na curva de progresso das doenças mancha branca e cercosporiose, quando comparadas àquelas aplicações de fungicidas realizadas após o início do estágio reprodutivo, uma vez que nesta situação, há maior severidade.

Ao avaliar a área foliar total das plantas ou área foliar sadia, conforme esperado, as menores áreas foram obtidas nos tratamentos com remoção artificial de folhas, independentemente da posição de sua

Tabela 4. Área foliar total (AFT), percentual de área foliar lesionada (AFL), percentual total de área foliar perdida (TAFP) (área foliar lesionada + área foliar retirada artificialmente) e índice de área foliar total (IAFt) em plantas de milho submetidas a diferentes épocas de aplicação de fungicida. Rio Verde (GO), 2014

\begin{tabular}{|c|c|c|c|c|c|c|c|}
\hline \multirow{2}{*}{$\begin{array}{l}\text { Remoção de } \\
\text { folhas }\end{array}$} & \multirow{2}{*}{ Fungicidas } & \multicolumn{3}{|c|}{$\operatorname{AFT}\left(\mathrm{cm}^{2}\right)$} & \multicolumn{3}{|c|}{$\operatorname{AFL~(\% )}$} \\
\hline & & VT & R1 & $\mathrm{R} 2$ & VT & $\mathrm{R} 1$ & R2 \\
\hline Sem remoção & - & $4.297 \mathrm{fA}$ & $3.146 \mathrm{fB}$ & $2.750 \mathrm{eC}$ & $43,28 \mathrm{fA}$ & $58,48 \mathrm{fB}$ & $63,69 \mathrm{dC}$ \\
\hline Sem remoção & B & $6.346 \mathrm{bA}$ & $4.751 \mathrm{bB}$ & $4.527 \mathrm{bC}$ & $16,23 \mathrm{dA}$ & $37,29 \mathrm{~dB}$ & $40,25 \mathrm{bC}$ \\
\hline Sem remoção & $\mathrm{C}$ & $6.745 \mathrm{aA}$ & $5.699 \mathrm{aB}$ & $5.533 \mathrm{aC}$ & $10,98 \mathrm{cA}$ & $24,78 \mathrm{cB}$ & $26,97 \mathrm{aC}$ \\
\hline 3 do terço médio & $\mathrm{C}$ & $4.822 \mathrm{eA}$ & $4.078 \mathrm{cB}$ & $3.688 \mathrm{cC}$ & $11,36 \mathrm{cA}$ & $21,17 \mathrm{aB}$ & $26,31 \mathrm{aC}$ \\
\hline 6 do terço médio & $\mathrm{C}$ & $2.956 \mathrm{hA}$ & $1.910 \mathrm{gB}$ & $1.753 \mathrm{fC}$ & $10,98 \mathrm{cA}$ & $24,78 \mathrm{cB}$ & $26,86 \mathrm{aC}$ \\
\hline 3 do terço superior & $\mathrm{C}$ & $4.845 \mathrm{eA}$ & $3.925 \mathrm{~dB}$ & $3.584 \mathrm{cC}$ & $11,04 \mathrm{cA}$ & $23,19 \mathrm{bB}$ & $27,69 \mathrm{aC}$ \\
\hline 6 do terço superior & $\mathrm{C}$ & $3.199 \mathrm{gA}$ & $1.790 \mathrm{gB}$ & $1.702 \mathrm{fB}$ & $7,78 \mathrm{aA}$ & $26,38 \mathrm{cB}$ & $27,53 \mathrm{aB}$ \\
\hline Sem remoção & - & $43,28 \mathrm{fA}$ & $58,48 \mathrm{fB}$ & $63,69 \mathrm{eC}$ & $3,01 \mathrm{fA}$ & $2,20 \mathrm{eB}$ & $1,93 \mathrm{eC}$ \\
\hline Sem remoção & A & $28,27 \mathrm{cA}$ & $52,02 \mathrm{eB}$ & $55,59 \mathrm{dC}$ & $3,80 \mathrm{cA}$ & $2,54 \mathrm{~dB}$ & $2,36 \mathrm{dC}$ \\
\hline Sem remoção & $\mathrm{B}$ & $16,23 \mathrm{bA}$ & $37,29 \mathrm{bB}$ & $40,25 \mathrm{bC}$ & $4,44 \mathrm{bA}$ & $3,33 \mathrm{bB}$ & $3,17 \mathrm{bC}$ \\
\hline Sem remoção & $\mathrm{C}$ & $10,98 \mathrm{aA}$ & $24,78 \mathrm{aB}$ & $26,97 \mathrm{aC}$ & $4,72 \mathrm{aA}$ & $3,99 \mathrm{aB}$ & $3,87 \mathrm{aC}$ \\
\hline 3 do terço inferior & $\mathrm{C}$ & $34,42 \mathrm{dA}$ & $47,84 \mathrm{~dB}$ & $53,95 \mathrm{dC}$ & $3,48 \mathrm{dA}$ & $2,77 \mathrm{cB}$ & $2,44 \mathrm{dC}$ \\
\hline 6 do terço inferior & $\mathrm{C}$ & $60,98 \mathrm{hA}$ & $74,78 \mathrm{gB}$ & $76,89 \mathrm{fC}$ & $2,07 \mathrm{hA}$ & $1,34 \mathrm{fB}$ & $1,23 \mathrm{fC}$ \\
\hline 3 do terço médio & $\mathrm{C}$ & $36,36 \mathrm{eA}$ & $46,17 \mathrm{cB}$ & $51,31 \mathrm{cC}$ & $3,38 \mathrm{eA}$ & $2,85 \mathrm{cB}$ & $2,58 \mathrm{cC}$ \\
\hline 6 do terço médio & $\mathrm{C}$ & $60,98 \mathrm{hA}$ & $74,78 \mathrm{gB}$ & $76,86 \mathrm{fC}$ & $2,07 \mathrm{hA}$ & $1,34 \mathrm{fB}$ & $1,23 \mathrm{fC}$ \\
\hline 3 do terço superior & $\mathrm{C}$ & $36,04 \mathrm{eA}$ & $48,19 \mathrm{~dB}$ & $52,69 \mathrm{cC}$ & $3,39 \mathrm{eA}$ & $2,75 \mathrm{cB}$ & $2,51 \mathrm{cC}$ \\
\hline 6 do terço superior & $\mathrm{C}$ & $57,78 \mathrm{gA}$ & $76,38 \mathrm{gB}$ & $77,53 \mathrm{fB}$ & $2,24 \mathrm{gA}$ & $1,25 \mathrm{gB}$ & $1,19 \mathrm{fB}$ \\
\hline
\end{tabular}

Fungicidas: $\mathrm{A}=$ [piraclostrobina + epoxiconazol $]+$ mancozebe $\left([33,25+12,5]+525 \mathrm{~g} \mathrm{ha}^{-1}\right) ; \mathrm{B}=[$ piraclostrobina + epoxiconazol $]+$ mancozebe $\left([66,5+25]+1050 \mathrm{~g} \mathrm{ha}^{-1}\right) ; \mathrm{C}=[$ piraclostrobina + epoxiconazol $]+$ mancozebe $\left([99,75+37,5]+1575 \mathrm{~g}^{-1}\right)$. Médias seguidas pela mesma letra minúscula na coluna e maiúscula na linha não diferem entre si pelo teste Scott-Knott e Tukey $(p \leq 0,05)$, respectivamente. 
remoção na planta ou época de aplicação dos fungicidas (Tabela 4).

De acordo com os valores observados em cada época de aplicação, verificou-se redução significativas da área foliar sadia em função da maior severidade das doenças, conforme o retardamento das aplicações de fungicidas. Fato melhor visualizado nos tratamentos testemunha e com redução de doses dos fungicidas e sem remoção artificial de folhas, tanto em percentual de área foliar lesionada (\%AFL) como em percentual total de área foliar perdida (\%TAFP) (área foliar lesionada + área foliar removida). Nesses, o percentual de área foliar perdida nas testemunhas (sem remoção de folhas), ou seja, somente em função das doenças, foram 43,28\% (VT); 58,48\% (R1) e 63,69\% (R2). Em função da redução de área foliar pela remoção artificial de folhas ter sido constante nos diferentes tratamentos, pode se inferir que, proporcionalmente, o gradiente do percentual de dano entre os tratamentos com retiradas de três ou seis folhas em cada época de aplicação foi oriundo apenas das diferenças existentes para a severidade das doenças foliares que ocorreram no milho (Tabela 4).

Ao calcular o índice de área foliar total (IAFt), verificou-se o mesmo comportamento expresso pelos percentuais de área foliar necrosada por doença na planta (Tabela 4). Portanto, os menores índices foram verificados quando se agregou a retirada de folhas artificialmente àqueles causados apenas pelas doenças, conforme a época de aplicação dos fungicidas (VT, R1 e R2).

Ao avaliar os rendimentos, verificou-se diferenças significativas para massa de mil grãos e produtividade entre os tratamentos (Tabela 5). A massa de mil grãos foi maior nos tratamentos que receberam fungicidas sem remoção artificial de folhas, independentemente da dose ou época de aplicação. Quando se removeu seis folhas do terço médio ou superior das plantas, independente da época de aplicação (VT, R1 e R2), refletiu em menor massa de mil grãos em relação aos demais tratamentos, mesmo em relação à testemunha. Ressalta-se ainda que, a retirada de 6 folhas do terço inferior para todas as épocas de aplicação, correspondeu a efeito prejudicial na massa de grãos similar à testemunha (sem remoção e sem aplicação de fungicida).

Para produtividade, também se observou o mesmo comportamento ocorrido para massa de mil grãos, pois são variáveis dependentes (Tabela 5). Da mesma forma, sem remoção artificial de folhas, maiores produtividades foram verificadas com os tratamentos que receberam fungicidas, independente da dose ou época de aplicação, porém, quando se retirou seis folhas do terço médio ou superior das plantas de milho, independentemente da época de aplicação (VT, R1 e R2), refletiu em menores produtividades em relação aos demais tratamentos, mesmo em relação à testemunha.

Esses dados se relacionam com os tratamentos com os menores índices de área foliar total (Tabela 4). Essa observação reforça os resultados obtidos por Fancelli (10), que verificou maior rendimento das plantas de milho quando as folhas na altura da espiga e aquelas logo acima mantiveram-se íntegras, em comparação com as perdas de folhas do terço inferior da planta.

Segundo Ottman e Welch (18) a radiação fotossinteticamente ativa que é interceptada exerce grande influência na produtividade do milho quando associado a outros fatores ambientais favoráveis. Folhas localizadas na parte superior da planta recebem mais radiação luminosa, o que resulta em área foliar fisiologicamente ativa para produção de fotoassimilados para que possa ocorrer o enchimento dos grãos. A perda dessas folhas, por doenças ou qualquer outro evento, tem impactos na produtividade, como foi observado no presente trabalho.

Mesmo com o comprometimento no índice de área foliar total, houve produção após a retirada de seis folhas no terço superior da planta, variando de 4.660,27 $\mathrm{kg} \mathrm{ha}^{-1}$ (VT) a 3.748,50 $\mathrm{kg} \mathrm{ha}^{-1}$ (R2), porém, significativamente inferior à testemunha com redução de área foliar por doenças, variando de $7.769,51 \mathrm{~kg} \mathrm{ha}^{-1}$ (VT) a 6.486,25 $\mathrm{kg} \mathrm{ha}^{-1}$ (R2) (Tabela 5). Alvim et al. (2) avaliando a redução da área foliar em plantas de milho na fase reprodutiva, encontraram resultados semelhantes, uma vez que a remoção de folhas acima da espiga, no terço superior da planta, prejudicou significativamente a produtividade das plantas de milho.

Bortolini e Gheller (4) avaliaram a aplicação de diferentes fungicidas no controle de doenças foliares na cultura do milho em relação à produtividade, observaram que, o emprego de fungicidas resultou em melhor controle e diminuição de doenças foliares, principalmente ferrugem polissora e mancha de cercospora, o que refletiu na produtividade. Foi observado neste trabalho que os tratamentos envolvendo utilização de fungicidas sem a retirada de folhas apresentaram resultados superiores para massa de mil grãos e produtividade.

Tabela 5. Massa de mil grãos e produtividade de plantas de milho submetidas com diferentes épocas de aplicação de fungicida com e sem retirada artificial de folhas em plantas, no período da segunda safra. Rio Verde (GO), 2014

\begin{tabular}{|c|c|c|c|c|c|c|c|}
\hline \multirow{2}{*}{ Remoção de folhas } & \multirow{2}{*}{ Fungicidas } & \multicolumn{3}{|c|}{ Massa de mil grãos (g) } & \multicolumn{3}{|c|}{ Produtividade $\left(\mathrm{kg} \mathrm{ha}^{-1}\right)$} \\
\hline & & VT & R1 & $\mathrm{R} 2$ & VT & R1 & R2 \\
\hline Sem remoção & - & $218 \mathrm{cA}$ & $189 \mathrm{bB}$ & $188 \mathrm{bC}$ & $7.769 \mathrm{bA}$ & $6.844 \mathrm{bB}$ & $6.486 \mathrm{bC}$ \\
\hline Sem remoção & B & $267 \mathrm{aA}$ & $218 \mathrm{aB}$ & $203 \mathrm{aC}$ & $9.148 \mathrm{aA}$ & $7.901 \mathrm{aB}$ & $7.093 \mathrm{aC}$ \\
\hline Sem remoção & $\mathrm{C}$ & $274 \mathrm{aA}$ & $222 \mathrm{aB}$ & $205 \mathrm{aC}$ & $10.189 \mathrm{aA}$ & $8.319 \mathrm{aB}$ & $7.153 \mathrm{aC}$ \\
\hline 3 do terço médio & $\mathrm{C}$ & $234 \mathrm{cA}$ & $199 \mathrm{bB}$ & $193 \mathrm{bC}$ & $8.227 \mathrm{bA}$ & $6.905 \mathrm{bB}$ & $6.466 \mathrm{bC}$ \\
\hline 6 do terço médio & $\mathrm{C}$ & $197 \mathrm{dA}$ & $153 \mathrm{cB}$ & $148 \mathrm{cC}$ & $5.693 \mathrm{cA}$ & $4.876 \mathrm{cB}$ & $4.668 \mathrm{cC}$ \\
\hline 3 do terço superior & $\mathrm{C}$ & $234 \mathrm{cA}$ & $202 \mathrm{bB}$ & $189 \mathrm{bC}$ & $8.224 \mathrm{bA}$ & $6.687 \mathrm{bB}$ & $6.067 \mathrm{bC}$ \\
\hline 6 do terço superior & $\mathrm{C}$ & $190 \mathrm{dA}$ & $154 \mathrm{cB}$ & $136 \mathrm{cC}$ & $4.660 \mathrm{cA}$ & $4.031 \mathrm{cB}$ & $3.748 \mathrm{dC}$ \\
\hline
\end{tabular}

Fungicidas: $\mathrm{A}=[$ piraclostrobina + epoxiconazol $]+$ mancozebe $\left([33,25+12,5]+525 \mathrm{~g} \mathrm{ha}^{-1}\right) ; \mathrm{B}=[$ piraclostrobina + epoxiconazol $]+$ mancozebe $([66,5+25]+1050$ $\left.\mathrm{g} \mathrm{ha}^{-1}\right) ; \mathrm{C}=[$ piraclostrobina + epoxiconazol $]+$ mancozebe $\left([99,75+37,5]+1575 \mathrm{~g} \mathrm{ha}^{-1}\right)$. Médias seguidas pela mesma letra minúscula na coluna e maiúscula na linha não diferem entre si pelo teste Scott-Knott e Tukey $(p \leq 0,05)$, respectivamente.] 
No entanto, pode-se inferir que para melhor resposta de um fungicida no controle de doenças foliares no milho, as aplicações deverão proporcionar maior cobertura das posicionadas no terço médio e superior das plantas, visto que estas são as que apresentam maior influência na determinação da produtividade de grãos nesta cultura. A remoção de três folhas do terço inferior na época de aplicação em VT não afetou a produtividade, quando comparada ao tratamento que recebeu apenas a associação fungicida na maior dose avaliada, tratamento que apresentou maior sanidade da planta (menor severidade), ao contrário do que ocorreu nos tratamentos com remoção de folhas do terço superior da planta. Para os estádios R1 e R2, a retirada de três folhas do terço inferior apresentou produtividade similar às doses de fungicida onde não houve remoção de folhas (Tabela ${ }^{\circ}$ ).

Camacho et al. (7), trabalhando com caracterização de genótipos de milho em relação à área foliar e coefíciente de extinção de luz, identificaram que cerca de $50 \%$ dos fotoassimilados acumulados nos grãos de milho são produzidos pelas folhas localizadas no terço superior da planta. Alvim et al. (1) mostraram a importância das folhas superiores da planta quanto à eficiência para a produção e ao fornecimento de fotoassimilados usados no enchimento de grãos, pois a remoção do limbo foliar acima da espiga resulta em maiores perdas de produção de grãos do que a remoção do limbo foliar abaixo da espiga. Folhas inseridas nas diferentes posições do colmo do milho também irão contribuir diferencialmente no suprimento de metabólitos para as demais partes da planta (13).

Maiores progressos das doenças (AACPD) foliares foram observados nas plantas de milho que não receberam aplicação de fungicidas, seguidos por àquelas em que menores doses da associação entre os produtos foram utilizadas.

Aplicações dos fungicidas em estádios fenológicos mais tardios (R1 e R2), resultou no aumento na severidade das doenças, repercutindo em danos na área foliar das plantas.

As menores áreas foliares total foram verificadas nos tratamentos onde se retirou artificialmente seis folhas, independentemente da posição de remoção da planta ou época de aplicação dos fungicidas.

$\mathrm{O}$ índice de área foliar total quando reduzido, em função da ocorrência de doenças, afeta negativamente no rendimento da cultura quando comparado a sua redução devido à retirada artificial de folhas na planta.

Maiores valores de massa de grãos e produtividade foram obtidos nos tratamentos com uso de fungicidas sem remoção artificial de folhas, independentemente da época de aplicação.

\section{REFERÊNCIAS}

1. Alvim, K.R.T.; Brito, C.H.; Brandão, A.M.; Gomes, L.S.; Lopes, M.T.G. Quantificação da área foliar e efeito da desfolha em componentes de produção de milho. Ciência Rural, Santa Maria, v.40, n.5, p.1017-1022, 2010.

2. Alvim, K.R.T.; Brito, C.H.; Brandão, A.M.; Gomes, L.S.; Lopes, M.T.G. Redução da área foliar em plantas de milho na fase reprodutiva. Revista Ceres, Viçosa, v.58, n.4, p.413-418, 2011.

3. Bergamaschi, H.; Dalmago, G.A.; Borgonci, J.I.; Bianchi, C.A.M.; Muller, A.G.; Comiran, F.; Heckler, B.M.M. Distribuição hídrica no período crítico do milho e produção de grãos. Pesquisa Agropecuária Brasileira, Brasília, v.39, n.9, p.831-839, 2004.

4. Bortolini, A.M.M.; Gheller, J.A. Aplicação de diferentes fungicidas no controle de doenças foliares na cultura do milho em relação à produtividade. Revista Brasileira de Energias Renováveis, Palotina, v.1, n.1, p.109-121, 2011.

5. Brito, A.H.; Pinho, R.G.V.; Pozza, E.A.; Pereira, J.L.A.R.; Faria Filho, E.M. Efeito da cercosporiose no rendimento de híbridos comerciais de milho. Fitopatologia Brasileira, Lavras, v.32, n.6, p.32-36, 2007.

6. Brito, C.H.; Silveira, D.L.; Brandão, A.M.; Gomes, L.S.; Lopes, M.T.G. Redução de área foliar em milho em região tropical no Brasil e os efeitos em caracteres agronômicos. Interciência, Santiago, v.36, n.4, p.291-295, 2011.

7. Camacho, R.G.; Garrido, O.; Lima, M.G. Caracterizacion de nueve genótipos de maiz (Zea mays L.) en relación al área foliar y coeficiente de extinción de luz. Scientia Agrícola, Piracicaba, v.52, n.2, p.294-298, 1995.

8. Casa, R.T.; Reis, E.M.; Zambolim, L. Dispersão vertical e horizontal de conídios de Stenocarpella macrospora e Stenocarpella maydis. Fitopatologia Brasileira, Lavras, v.29, n.2, p.141-147, 2004.

9. Costa, D.F.; Vieira, B.S.; Lopes, E.A.; Moreira, L.C.B. Aplicação de fungicidas no controle de doenças foliares na cultura do milho. Revista Brasileira de Milho e Sorgo, Sete Lagoas, v.11, n.1, p. 98-105, 2012.

10. Fancelli, A.L. Fenologia do milho. Piracicaba: ESALQ/USP, 1988, 339p.

11. Fancelli, A.L.; Dourado Neto, D. Produção de milho. Guaíba: Agropecuária, $2000.360 \mathrm{p}$.

12. Ferreira, D.F. Sisvar: a computer statistical analysis system. Ciência e Agrotecnologia, Lavras, v.35, n.6, p.1039-1042, 2011.

13. Fornasieri Filho, D. Manual da cultura do milho. Jaboticabal: Funep, 2007. $576 \mathrm{p}$.

14. Magalhães, P.C.; Durães, F.O.M. Fisiologia da produção de milho. Sete Lagoas: Embrapa Milho e Sorgo, 2006. 10p. (Embrapa Milho e Sorgo. Circular Técnica, 76).

15. Malagi, G.; Santos, I.; Camochena, R.C.; Moccellin, R. Elaboração e validação da escala diagramática para avaliação da mancha branca do milho. Revista Ciência Agronômica, Fortaleza, v.42, n.3, p.797-804, 2011.

16. Marchi, S.L. Interação entre desfolha e população de plantas na cultura do milho na região oeste do Paraná. 2008. 58 f. Dissertação (Mestrado em Agronomia) - Universidade Estadual do Oeste do Paraná, Campus de Marechal Cândido Rondon, 2008.

17. Moratelli, G.; Kaefer, K.A.C.; Ertel, F.; Vogt, R.T.; Ferreira, S.D.; Egewarth, V.A.; Mattei, E.; Rosa, W.B.; Egewarth, J.F. Effect of fungicide application times in the control management of leaf foliar diseases in maize. African Journal of Agricultural Research, Ago-Iwoye, v.10, n.38, p.3686-3695, 2015.

18. Ottman, M.J.; Welch, L.F. Planting patterns and radiation interception, plant nutrient concentration, and yield in corn. Agronomy Journal, Madison, v.81, n.2, p.167-174, 1989.

19. Pinto, N.F.J.A.; Angelis, B.; Habe, M.H. Avaliação da eficiência de fungicidas no controle da cercosporiose (Cercospora zeae-maydis) na cultura do milho. Revista Brasileira de Milho e Sorgo, Sete Lagoas, v.3, n.1, p.139-145, 2004

20. Rezende, W.S.; Brito, C.H.; Brandão, A.M.; Franco, C.J.F.; Ferreira, M.V.; Ferreira, A.S. Desenvolvimento e produtividade de grãos de milho submetido a níveis de desfolha. Pesquisa Agropecuária Brasileira, Brasília, v.50, n.3, p.203-209, 2015.

21. Santos, G.R.; Gama, F.R.; Gonçalves, C.G.; Rodrigues, A.C.; Leão, E.U.; Cardon, C.H.; Bonifácio, A. Severidade de doenças foliares e produtividade de genótipos de milho em resposta à adubação nitrogenada. Revista Ceres, Viçosa, v.60, n.4, p.505-513, 2013.

22. Shaner, G.; Finney, R.E. The effect of nitrogen fertilization on the expression of slow-mildewing resistance in knox wheat. Phytopathology, Saint Paul, v.67, n.8, p.1051-1056, 1977.

23. Silva, O.C.; Schipanski, C.A. Manual de identificação e manejo das doenças do milho. 2 ed. Castro: Fundação ABC, 2007. 116 p.

24. SYNGENTA. Sementes Milho: Fórmula Viptera. 2019. Disponível em: https://www.portalsyngenta.com.br/sementes-milho-formula-viptera Acesso em: 01/11/2019.

25. WEATHERBASE. Rio Verde, Goiás. 2019. Disponível em: <https://www. weatherbase.com/weather/weather.php3?s=597703\&cityname=Rio-Verde-Goias-Brazil>. Acesso em: 19/10/2019. 